\title{
A ESCRITA HISTORIOGRÁFICA PERMEADA PELA ESCRITA DE SI: O CASO DE COMO E POR QUE LER O ROMANCE BRASILEIRO
}

\author{
Juliana Tomkowski Mesko da Fonseca* \\ Universidade Federal do Rio Grande
}

\begin{abstract}
Resumo: Este artigo analisa Como e por que ler o romance brasileiro (2004), de Marisa Lajolo, à luz das teorias contemporâneas da História da Literatura. Busca-se refletir sobre como seu processo de escrita aponta para uma nova direção na articulação histórica do passado, contribuindo para a reestruturação dos tradicionais alicerces da teoria e história literárias. Para tanto, serão resgatadas algumas perspectivas teóricas consagradas acerca da escrita historiográfica em literatura, comparando-as com as reflexões de David Perkins, Siegfried Schmidt e Heidrun Olinto. O objetivo é demonstrar como, nessa obra, a personalidade da autora é fator determinante da construção do texto, a subjetividade desempenha um papel central nas escolhas teóricas e materiais. Lajolo revisita suas experiências de leitora e as torna parte constituinte de sua história da literatura. Nesse sentido, é um caso exemplar de como a construção do conhecimento histórico-literário passa a admitir a interferência de questões afetivas na mediação dos diversos elementos que o compõe.
\end{abstract}

Palavras-chave: História da literatura. Ego-história. Romance brasileiro. Autoria.

Para Kant, a experiência do prazer no belo é sucedida de uma incontornável necessidade de comunicá-la. Buscamos compartilhar esse sentimento com os outros, multiplicando-o pela adesão destes e assim conferindo uma potencial universalidade àquilo que era antes uma sensação da reflexão subjetiva. Esse movimento ocorre em Como e por que ler o romance brasileiro (LAJOLO, 2004a). Nesta obra, somos apresentados antes de tudo à Marisa Lajolo, crescida por entre páginas de livros e paisagens de muitos Brasis romanceados, repleta de vontade de contar as suas aventuras de leitora entusiasmada e partilhar conosco, do lado de cá, as suas impressões sobre os diversos escritores, fábulas e episódios que compõem a trajetória do romance nacional.

\section{c) (i) $\Theta$} EY No ND Esta obra está licenciada sob uma Licença Creative Commons.

\footnotetext{
* Mestranda em História da Literatura pelo Programa de Pós-Graduação em Letras da Universidade Federal do Rio Grande (FURG). Bolsista CAPES/DS.
} 
Se pensarmos, nos termos de David Perkins (1999), a escrita da história da literatura como narração, encontramos na obra em questão uma narrativa de memória afetiva em que as escolhas da historiadora são centradas explicitamente na sua experiência e gosto. Para Perkins, as histórias narrativas da literatura evidenciam sempre um assunto protagonista e um enredo, o qual demonstra as transformações sofridas pelo tema herói entre o ponto inicial e final de uma determinada história, todos escolhidos arbitrariamente pelo autor. Neste sentido, a obra de Lajolo ilumina, sob o olhar da menina, moça, mulher e professora Marisa, um gênero literário específico, de uma determinada nacionalidade: o romance brasileiro.

A autora confessa dessa história da literatura utiliza-se de recursos estéticos/estratégicos para se aproximar do leitor. O diálogo, estabelecido desde a primeira página, envolve e desafia a valorar gostos e desgostos em relação aos romances ali tratados. Escrito em ritmo de conversa, o livro não se encaixa nos métodos objetivistas de escrita historiográfica. Ao invés, é elaborado nos moldes da subjetividade sob a desvelada expressão discursiva da historiadora.

As ideias antecessoras a essa abordagem - que relativiza a verdade no plano do saber histórico e centraliza a figura do historiador no processo de escrita de histórias da literatura - podem ser traçadas desde a segunda metade do século XX. A partir desse período, as discussões acerca dos estudos historiográficos apontam para a recuperação da importância da história como ponto de vista epistemológico para a compreensão dos fenômenos literários. Tais reflexões desafiam as perspectivas, outrora consagradas, defensoras da objetividade e da neutralidade do observador no campo da pesquisa histórica.

Conforme Roberto Acízelo de Souza (1973), no século XIX os valores do cientificismo prevaleciam em todos os âmbitos do conhecimento, alcançando, assim, as análises sobre os acontecimentos históricos. A história, enquanto método de investigação, era vista como um instrumento de recuperação integral do passado e, dessa forma, passou a desempenhar um papel de festejada relevância nos estudos literários da época. As histórias da literatura produzidas no período foram pensadas, portanto, de acordo com modelos oriundos de bases positivistas e/ou evolucionistas - doutrinas científicas dominantes nos anos oitocentos - e buscavam abarcar um grande período temporal e vasta produção material, pretendendo-se completas e imparciais. Sob essa ótica, as portas do passado fecham-se em uma só possibilidade, excludente de tantas outras.

O pensamento nascido sob a égide novecentista, todavia, esquivou-se desse ponto de vista, afastando a história dos estudos da literatura. Para João Barrento (1986, p. 13), é no século XX 
[...] que se dá, numa perspectiva epistemológica, a passagem decisiva e generalizada da história para a estrutura, das preocupações genéticas para as fenomenológicas: na linguística (sincrônica/ estrutural), na filosofia (descritiva, analítica, fenomenológica, intuicionista), nos estudos literários (a "filosofia da ciência literária", os formalismos, a eternização da obra como manifestação intemporal nas orientações neo-idealistas).

As teorias de base formalista e estruturalista ${ }^{1}$ defendiam distanciamento, imparcialidade $\mathrm{e}$ objetividade, mas ao contrário da pratica científica do século anterior, privilegiavam a perspectiva sincrônica na análise literária ${ }^{2}$. Debruçando-se essencialmente sobre aspectos formais, esses postulados teóricos desacreditaram a investigação histórica da literatura, descartaram o contexto de produção artística e o observador/receptor como parte ativa da compreensão e significação da obra: “[...] procurava-se pensar a estrutura como processo e introduzir-se o sujeito no universo linguístico autossuficiente" (JAUSS, 2002, p. 68) ${ }^{3}$.

Foi na década de 1960, com as reflexões de Hans Robert Jauss, autor de um texto com o significativo título História da literatura como provocação à teoria literária, que a história da literatura ganhou um novo fôlego. A teoria da estética da recepção atribuiu relevância ao lugar histórico e às peculiaridades socioculturais, próprios do fazer literário. $\mathrm{O}$ discurso poético, nessa linha, é visto dentro de uma relação entre autor, obra e público em que a presença do observador é evidente.

Tal propósito não seria alcançável através da panaceia das taxionomias perfeitas, dos sistemas semióticos fechados e dos modelos formalistas de descrição, mas tão-só através de teoria da história que desse conta do processo dinâmico de produção e recepção (JAUSS, 2002, p. 71).

Nesse cenário de revalorização da história no âmbito dos estudos da literatura, ganharam força no pensamento acadêmico da época as teorizações de Walter Benjamin, produzidas algumas décadas antes ${ }^{4}$. Estas, simultaneamente, reafirmavam a história enquanto ciência e questionavam os dogmas dos métodos investigativos do século XIX. Se, antes, a imagem do historiador poderia ser a de uma pessoa com uma luneta em punho, capaz de enxergar de longe cores e formas com a mesma

\footnotetext{
${ }^{1}$ Tratamos, aqui, de maneira rápida esse ramo dos estudos literários não por desconsiderarmos a importância desse método investigativo acerca da literatura, mas porque a linha cronológica que procuramos estabelecer objetiva demonstrar a trajetória do pensamento historiográfico no sentido de reconhecer a presença do observador crítico e o historiador como sujeito ativo/construtor/seletivo na pesquisa histórica. Para uma melhor compreensão das teorias imanentistas em questão Cf. EIKHENBAUM, B. et. al. Teoria da literatura. Formalistas russos. Porto Alegre: Globo, 1971. E também: EAGLETON, Terry. Teoria da Literatura: uma introdução. São Paulo: Martins Fontes, 2006.

${ }^{2}$ Entretanto, há no pensamento de Tynianov um inovador caminho para pensar as relações entre literatura, história, cultura e sociedade. Bastante diferente das reflexões que lhe eram contemporâneas, o pensador russo teoriza no sentido de uma conjugação entre os estudos sincrônico e diacrônico da literatura. Cf. TYNIANOV, J. Da evolução literária. In: EIKHENBAUM, B. et. al. Teoria da literatura. Formalistas russos. Porto Alegre: Globo, 1971. p. 105-118.

${ }^{3}$ Cf., para maiores desenvolvimentos, JAUSS, Hans Robert. A história da literatura como provocação à teoria literária.

Trad. de Sérgio Tellaroli. São Paulo: Ática, 1994.

${ }^{4}$ Cf. as Teses sobre a História (BENJAMIN, 1994).
} 
nitidez com que são vistas de perto - um grande braço que vai ao passado e recupera-o em sua totalidade - a partir de então, a pesquisa histórica passou a ser vista de maneira caleidoscópica, aberta e plural. Segundo Barrento (1986, p. 11-12):

É precisamente aqui que reside a grande diferença entre o "sentido da história" [...] do historicismo do século XIX, monumental, soi-disant objetivo, pretendendo tudo abarcar sem distinções [...] e o conceito de história de um autor como Walter Benjamin: um sentido histórico subjetivamente seletivo, objetivamente relacionado, não com a "totalidade" [...], abstrata e inapreensível, de um tempo/momento histórico passado, mas antes com o caráter específico do presente do sujeito de consciência histórica, e vendo a História como um processo, não meramente aditivo, mas construtivo, não linearmente contínuo nem circularmente cíclico, mas descontínuo, "quebrado". [...] A história funciona como organon de um autoconhecimento e abre, a partir do passado, os caminhos do presente - sem a transfiguração do monumentalismo objetivista do historicismo [...]. História não é aqui progressão linear ingenuamente desproblematizada, mas visão crítica e consciente do nosso lugar no tempo.

O pensamento de Benjamin aponta para uma nova direção na articulação histórica do passado, contribuindo para a reestruturação dos tradicionais alicerces da teoria e histórias literárias. Nessa perspectiva, a fragmentação e as múltiplas faces dos tempos idos fazem-se vigentes, há a quebra da linearidade e unidimensionalidade atribuída à investigação histórica pelos postulados teóricos anteriores. O passado "é sempre transformado e renovado pela(s) consciência(s) do presente desse passado, e só assim é História viva e não matéria inerte" (BARRENTO, 1986, p. 9). Dessa forma, toda visão histórica é uma visão crítica acerca do antes e do agora, que pressupõe um sujeito responsável por construir uma ponte entre os tempos. O historiador, nesse papel, é um observador seletivo que simula os passos da história através dos critérios por si estabelecidos.

Nesse mesmo sentido caminha o pensamento de Siegfried Schmidt (1996). Para o autor, uma história da literatura é, antes de tudo, uma construção retrospectiva de um historiador que, baseado em conceitos teóricos previamente determinados, busca organizar discursivamente uma cadeia de acontecimentos de acordo com suas motivações e intenções. Portanto, não deveríamos julgar o valor dessas obras pela exata correspondência, ou não, com relação aos dados ou eventos históricos focalizados.

Sua ciência empírica da literatura estabelece relações entre o discurso poético e o contexto social, estético e cultural em que está inserido. Propõe, sob o ponto de vista construtivista, que se analisem as mudanças literárias como mudanças sociais, isto é, que se considere a literatura como um sistema social entre outros, e não como uma esfera separada. O teórico alemão indica novos caminhos a serem trilhados na escrita de histórias da literatura, muito mais abertos à subjetividade e sensibilidade do autor. Para ele, o passado é uma ficção, os dados históricos não chegam prontos ao historiador, como fatos objetivos. Antes, os fragmentos do passado precisam ser interpretados, 
construídos a partir de teorias e métodos. O que o historiador faz é elaborar uma cadeia narrativa plausível intersubjetivamente em que a história apareça por meio da organização dos argumentos, mas nunca como verdade absoluta. Nas palavras de Heidrun Olinto (2008, p. 39),

No interior do projeto de uma ciência da literatura empírica questionava-se, com frequência, uma postura sistemática da consciência polarizada entre razão teórica e razão prática, contrapondo-lhe uma consciência não dualista que articula as duas e, ainda, estendendo o modelo à superação da dicotomia entre racionalidade e emotividade. Trata-se de uma transformação que sinaliza, antes de mais nada, o papel da co-presença de valores afetivos em todas as formas de construção do conhecimento.

A pesquisadora alemã observa que gradualmente se abre espaço no discurso intelectual para a espontaneidade e as emoções, tornando evidente a autoria no processo de produção do conhecimento. Essa perspectiva autoriza o escritor à reflexão desvelada no desenvolvimento de histórias da literatura, privilegiando o caráter construtivo da pesquisa sem, contudo, significar um total desapreço a dados documentais e comprovação de fatos registrados.

Revisitando os caminhos da historiografia literária no sentido pretendido por Schmidt (1996) - de que o estudo da história nunca alcançará o passado tal como ele ocorreu; mas de que seu valor científico está em outro plano: 1) na maneira como captura a experiência e a transmite; 2) na linguagem intersubjetiva; 3) na valorização e no aprendizado com as pesquisas já feitas para possibilitar uma ampliação da compreensão do passado - encontramos em Gumbrecht o precursor do "articulador auto-reflexivo" (OLINTO, 2008, p. 38) que põe em evidencia a presença do autor em sua obra. Em seu livro Uma história da literatura espanhola, Gumbrecht inova a maneira de escrever histórias literárias. Suas palavras, colocadas ao lugar do subtítulo, são ilustrativas desse processo do conhecimento legitimador da personalidade do autor como fator determinante na construção do texto: "O título desse livro sublinha tão somente que hoje, de qualquer modo, deveria ser evidente, portanto quase uma tautologia: que não pode haver observação sem observadores" (GUMBRECHT apud OLINTO, 2008, p. 38).

Percebemos, a partir dessa ilustração, que a subjetividade passa a desempenhar papel central na elaboração de histórias da literatura, nas escolhas teóricas e materiais. Torna-se legitimo, dessa forma, a interferência de questões afetivas na mediação dos diversos elementos presentes na tarefa de narrar. Nessa linha teórica inscreve-se a escrita de Marisa Lajolo em Como e por que ler o romance brasileiro. A grande inovação dessa história da literatura nacional é a voz da autora bem marcada a cada página, guiando-nos por meio de suas impressões da literatura brasileira. O próprio recorte de gênero, já apresentado no título, é a primeira escolha autoral explícita da qual somos informados. As páginas que seguem vão tratar sobre o romance brasileiro porque a autora é dele 
"Leitora apaixonada, fã de carteirinha [...]” (2004a, p.13). E quanto mais avançamos em sua leitura, mais nos fica claro a mão pesada de quem escreve, sempre presente, acompanhando a história que se propôs contar. A obra é um modelo dos “experimentos de historiografia literária que acentuam questões de afeto e emoção na mediação entre aspectos psíquicos, sistemas sociais, comportamentos culturais e escolhas políticas" (OLINTO, 2008, p. 35).

O título - Como e por que ler o romance brasileiro - oferece, conforme Lajolo (2004b), uma dupla homenagem: em primeiro lugar, ao crítico Harold Bloom, escritor de Como e por que ler; e adicionalmente ao escritor José de Alencar, por seu Como e por que sou romancista. Além disso, o nome nos remete diretamente aos objetivos do livro. Afastando-se da historiografia tradicional, a obra de Lajolo assume a missão de nos conduzir por um vasto acervo literário produzido no Brasil, mas não se limita a isso: procura justificar e incentivar a leitura do romance nacional. Também a forma com que nos é apresentada esta história é inventiva. A ordenação dos capítulos não segue a separação em que estudiosos acostumados à sistematização de períodos literários se sentem mais confortáveis, tais quais: Romantismo, Realismo ou Modernismo. A autora prefere enredar os tempos, traçando capítulos por eixos temáticos ao sabor de sua vontade, facilitando, assim, explanações mais intimistas.

A obra é dividida em sete partes: "Como e por que leio o romance brasileiro", "O romance e a leitura sob suspeita", "Ler e escrever no feminino", "O Brasil no mapa do romance", "O romance viaja pelo Brasil", "Histórias da história invadem o romance" e "Romances e leitores: queda de braço sempre recomeçada". A resposta para a pergunta da qual somos inquiridos no título não vem prontamente explicita às poucas linhas da introdução, mas vai sendo conquistada aos poucos, no vagar das páginas lidas e apresentações feitas por Lajolo, romance após romance.

Desde o começo a historiadora busca estabelecer intimidade com o leitor fazendo confissões de sua vida privada e profissional, vinculando tais experiências ao estudo e leitura de romances. Não se trata, no entanto, de um simples ensaio memorialístico:

\footnotetext{
As memórias precisam ser convocadas, evocadas, confrontadas, porque nenhuma delas, individualmente ou em conjunto, constituem a história. [...] esta se constrói pela escolha e pela construção de um objeto de investigação, uma operação que pode iniciar-se com a evocação de lembranças, mas que não pode levar à redução da história a essas memórias individuais (OLINTO, 2004, p.24).
}

A cada novo capítulo encontramos uma citação de Monteiro Lobato, escritor caro à Marisa leitora e pesquisadora acadêmica que nos apresenta, nas palavras do autor, os temas abordados por entre fatos, registros históricos e lembranças. A trajetória de leitura da historiadora abre as cortinas 
de Como e por que ler. Somos transportados à "poltrona gorda e velha" (LAJOLO, 2004a, p. 15), em Santos, que abrigou a então jovem autora dessa história da literatura durante seu mergulho nas páginas de Inocência, de Taunay, primeiro romance inteiramente lido por ela, e chegamos até os anos 2000, com a voz marginal de Ferréz ecoando da periferia paulistana, para logo então, abrir o olhar em uma perspectiva mais ampla: a da história da leitura no Brasil.

Nascido na Europa como forma de entretenimento, o romance trouxe cenários e faces do cotidiano às páginas dos livros, popularizando dessa forma a leitura. A literatura, antes voltada à população mais erudita, ganha no gênero romanesco uma versão democrática, cujo objetivo principal era divertir seus leitores. E, por isso, foi odiado por muitos, tanto no seu continente de origem quando nas novas terras em que veio aportar (LAJOLO, 2004a).

O romance desembarca em solo brasileiro com carregado sotaque afrancesado para, aos poucos, pintar-se da cor local. Lajolo aponta para o fato de que o acesso aos livros era bastante difícil em um primeiro momento; a escassez de meios de impressão e a submissão à cultura portuguesa contribuíram para isso. Segundo a autora, muitas foram as razões que possibilitaram o reconhecimento e consequente sucesso desse gênero na terra brasilis. Assim como nos países europeus, a divulgação em folhetins veiculados em jornais facilitou sua popularização. E, aos poucos, o gênero foi ganhando identidade e status com acento tropical, sendo que as mulheres tiveram uma participação decisiva na formação de um público leitor expressivo.

O enaltecimento das qualidades brasileiras; a afirmação do universo nacional: cenário, cultura e povo na literatura; a transposição da elegância europeia às paginas dos romances do nosso país; a celebração da corte e da cidade maravilhosa; ou, ainda, o desmantelamento das imagens de um Brasil idealizado na literatura, com o surgimento de outros Brasis, regionais e urbanos, são assuntos abordados no livro sob a perspectiva de uma leitora.

Nesse sentido, voltando aos conceitos de Perkins (1999), o enredo central da narrativa de Lajolo é o desenvolvimento do gênero e da leitura no país. Porém, a análise da autora ciclicamente se movimenta ao redor desse eixo, indo e voltando entre tempos e autores de maneira idiossincrática. A historiadora traça uma linha cronológica dos principais momentos do romance na cena nacional: dos primeiros escritores aos mais contemporâneos, usando de bastante liberdade autoral na escolha das obras a serem analisadas. Trata-se, portanto, de "uma organização pouco canônica da literatura brasileira. É sempre um exercício intelectual interessante [...] rearrumar as gavetas que estavam todas arrumadinhas" (LAJOLO, 2004b). 
Lajolo enfatiza, no entanto, que a temporalidade buscada por ela para recuperar historicamente os caminhos percorridos pelo romance não podem ser confundidos com uma ideia evolucionista, típica do século XIX, atrelada à ideia de aperfeiçoamento:

[...] não acho que literatura, cultura e arte tenham uma evolução qualitativa. Entendo que há, digamos assim, um percurso ao longo do qual os perfis das obras vão mudando. Vão mudando, mas não piorando ou melhorando. Não acho que A Moreninha, que é um dos primeiros romances brasileiros, seja pior do que Dom Casmurro. Acho que A Moreninha é o melhor livro possível para os autores e leitores brasileiros de 1844 assim como Dom Casmurro é um dos melhores livros possíveis para os leitores do fim do século 19 (LAJOLO, 2004b).

Ao mesmo tempo em que celebra escritores já amplamente reconhecidos, como Clarice Lispector ou Guimarães Rosa, Lajolo (2004a) abre espaço para nomes pouco lembrados, como Ana Luísa de Azevedo Castro e Coelho Neto. Esses últimos, trazidos à tona como pontos de iluminação à discussão acerca da condição de subalternidade étnica. Sobre essa questão, motivadora de muitas opiniões controversas, Lajolo retoma obras de Bernardo Guimarães, Monteiro Lobato, Josué Montello e Conceição Evaristo para lembrar-nos do poder de influência do romance, o qual não oferece respostas fechadas, mas instaura a dúvida e o questionamento: "[...] pois ele não apenas envolve os leitores na história que conta, mas exige que tomem partido face ao que leem" (LAJOLO, 2004a, p. 32).

É nesse espírito de provocar inquietação que se constrói essa bem diferente história da literatura nacional. Ali encontramos exemplos de como os argumentos emotivos podem ser fatores determinantes na construção de narrativas histórico-literárias. Apesar de haver um trabalho de resgate de fatos e registros do passado, os critérios da pesquisa desenvolvida são permeados pela afetividade do historiador de forma simbólica.

É exatamente por ser atônito que este olhar cria problemas para formas mais tradicionais de leitura literária... Onde o bom romance? E onde o resto (aliás: qual resto...?), sobretudo na pós-modernidade periférica, como se diz a brasileira? O leitor que responda por si (LAJOLO, 2004a, p. 26).

A autora planta, contando a sua experiência, a semente da curiosidade em seu leitor. Este, após navegar pelos mares do romance sob o olhar atento de Lajolo, se sentirá instigado a fazer sua própria incursão pelas tantas linhas da literatura nacional. Ao final, em meio a tantas memórias e pessoalidades compartilhadas pela escritora de Como e por que ler, o grande protagonista dessa narrativa é o romance brasileiro.

\section{Referências}


BARRENTO, João. O regresso de Clio? Situação e aporias da história literária. In: . (Org.). História literária: Problemas e perspectivas. 2.ed. Lisboa: Materiais Críticos, 1986.

BENJAMIN, W. Magia e Técnica, arte e Politica: ensaios sobre literatura e história da cultura. Tradução de Paulo Sérgio Rouanet. São Paulo: Brasiliense, 1994. (Obras escolhidas. Vol. I).

JAUSS, Hans Robert. A estética da recepção: colocações gerais. In: A literatura e o leitor: textos de estética da recepção. $2^{\mathrm{a}}$ ed. Rio de Janeiro: Paz e Terra, 2002.

LAJOLO, Marisa. Como e por que ler o romance brasileiro. Rio de Janeiro: Objetiva, 2004.

. Marisa Lajolo põe o Brasil no mapa do romance. Jornal da Unicamp. Campinas, 11-17 out. 2004. p. 8 .

GUMBRECHT, H.U. Eine Geschichte der Spanischen Literatur. Frankfurt: Suhrkamp, 1990.

OLINTO, Heidrun Krieger. Uma história literária afetiva. Cadernos de Pesquisa em Literatura, v. 1, p. 34-46, 2008.

Momentos de presença na história dos estudos de literatura. Cadernos do Centro de Pesquisas Literárias da PUC/RS, Porto Alegre, v. 10, n.1 p. 22-27, set. 2004.

PERKINS, David. História da literatura como narração. Trad: Maria Ângela Aguiar. Cadernos do Centro de Pesquisas Literárias da PUC/RS, Porto Alegre,v.3, n.1, mar.1999. Série Traduções.

SCHMIDT, Siegfried J. Sobre a escrita de histórias da literatura. In: OLINTO, Heidrun Krieger (Org.). Histórias de literatura: as novas teorias alemãs. São Paulo: Ática, 1996.

SOUZA, Roberto Acízelo de. História da literatura. In: Formação da teoria da literatura: inventário de pendências e protocolo de intenções. Rio de janeiro: Ao livro Técnico; Niterói: UFF, 1973. p. $62-85$.

[Recebido em julho de 2012 e aceito para publicação em outubro de 2012]

\title{
Historiographical writing through the writing of the self: the case of Como e por que ler o romance brasileiro
}

\begin{abstract}
This article analyses Como e por que ler o romance brasileiro (2004) by Marisa Lajolo through contemporary theories about history of literature. It is aimed a reflection on how its writing process points to a new direction regarding historical conceptions of the past, thus contributing to the restructuring of literary history's and theory's traditional groundings. In order to do so, relevant theoretical perspectives on the historiographical writing of literature will be compared with the reflections of David Perkins, Siegfried Schmidt and Heidrun Olinto. The purpose is to show how, in that work, the author's personality is a crucial factor on the fabric of the text. Subjectivity plays an important role in theoretical and material writing choices. Lajolo revisits her experiences as a reader and turn them into an element of her history of literature. It is, therefore, an exemplar case on how the construction of historical-literary knowledge came to admit the meddling of affective matters in its plural constituent elements.
\end{abstract}


Keywords: History of literature. Brazilian Novel. Ego-history. Authorship.

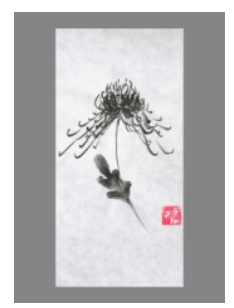

